\title{
Insights to the phase solubility diagrams of flurbiprofen with inclusion complex
}

\author{
Ayşe Nur OKTAY ${ }^{1,2 *}$ (D) \\ 1 Department of Pharmaceutical Technology, Faculty of Pharmacy, Gazi University, Ankara, Turkey \\ 2 Department of Pharmaceutical Technology, Gulhane Faculty of Pharmacy, University of Health Sciences, Ankara, \\ Turkey \\ * Corresponding Author. E-mail: aysenur.oktay@sbu.edu.tr (A.O.).
}

Received: 28 October 2020 / Revised: 27 December 2020 / Accepted: 16 January 2021

\begin{abstract}
Flurbiprofen (FB) is one of the nonsteroidal anti-inflammatory drugs with poor water solubility. Cyclodextrins have a special structure (hydrophobic inner phase and hydrophilic outer phase), which have been widely used to enhance the solubility and stability of drug substances in pharmaceutical applications. The present study is intended to improve the solubility of FB with the inclusion complexes assembled by using beta-cyclodextrin ( $\beta$-CD) and hydroxypropyl beta-cyclodextrin (HP $\beta-C D)$ and to perform the phase solubility studies to estimate the stability constant and complexation efficiency. The results of phase solubility studies showed that the $\mathrm{FB} / \beta-\mathrm{CD}$ complexes have $\mathrm{B}_{\mathrm{s}}$ type and FB/HP $\beta-C D$ complexes have $A_{L}$ type profiles in both PBS and water media. The interaction forces between FB and $\mathrm{HP} \beta-\mathrm{CD}$ were stronger than $\mathrm{FB}$ and $\beta$-CD for the formation of inclusion complex in water. Moreover, the complexation efficiency value of FB/HP $\beta$-CD complex in water media was found higher than the FB/HP $\beta$-CD complex in PBS media. These results of phase solubility studies absolutely demonstrated the advantage of HP $\beta$-CD instead of $\beta$-CD to obtain the inclusion complex with 1:1 Molar ratio in water and to improve the apparent water solubility of FB. According to these results, the FB/HP $\beta-C D$ inclusion complex was prepared with the Freeze-drying method and it was achieved to enhance the water solubility of FB 52.6-fold with using HP $\beta$-CD. In conclusion, the presence of the inclusion complex was successfully confirmed by differential scattering calorimetry, X-ray diffraction, scanning electron microscopy and fourier transform infrared analysis.
\end{abstract}

KEYWORDS: Flurbiprofen; phase solubility; cyclodextrins; inclusion complex; freeze-drying.

\section{INTRODUCTION}

Pain and inflammation are among the most frequently reported disorders and the major problems that clinical medicine tries to solve. Especially non-steroidal anti-inflammatory drugs are the most commonly used drug groups in analgesic and anti-inflammatory drugs. Aspirin is the prototype of this group of drugs and the most commonly used subgroup after aspirin are propionic acid derivatives. The flurbiprofen (FB) as an active substance also belongs to this group, and compared to indomethacin, ibuprofen and aspirin, FB has been proven to be more effective in terms of inhibition of prostaglandin. FB is 2-(3-fluoro-4-phenylphenyl) propanoic acid and it is commonly used in treatment of migraine pain, gout, osteoarthritis and rheumatoid arthritis, soft tissue injuries and post-operative ocular inflammation. However, with oral use of these drug groups, some undesirable side effects such as ulceration, abdominal burning, pain, cramping, nausea and gastritis occur. Moreover, since half-life is short (4 hours), there is a need for multiple dosing to achieve and maintain therapeutic concentration (50-75 $\mathrm{mg}$ single dose, 3-4 times a day). Therefore, topical application of this drug is highly desired. For the absorption of the drugs with topical applications, solubility and drug permeation through the skin are rate limiting steps. As FB is a low water-soluble drug (BCS class II), problems are observed in obtaining the desired effect. It is planned to solve the solubility problem of FB in this research.

The solubility of drug in the water is a key factor for the solubility of drug particles in the physiological fluids and its contribution to bioavailability [1]. Moreover, lack of efficiency related to the poor aqueous solubility causes failures during drug development [2]. On the market, most drugs have water solubility problem resulting in poor bioavailability, as the dissolution limits the absorption of drug [3,4]. Heimbach et 
al. indicated that the $40 \%$ of the currently available drugs on the market and approximately $90 \%$ of new drugs cannot achieve the therapeutic concentration in physiological fluids because of the low water solubility [5].

There are many techniques to increase the water solubility of hydrophobic drug substances. By means of using cosolvents or surfactants, preparing solid dispersions [6,7], complexes, self-emulsifying systems [8], salt formations and decreasing the particle size $[9,10]$ of drug substances; the water solubility of drugs may be increased. The use of surfactants or cosolvents may lead to increased side effects. For example, Willems et al. 2011 reported that the use of Cremophor EL increases the toxicity of Taxol and cyclodextrin, and it causes the nephrotoxicity of itraconazole in Sporanox ${ }^{\circledR}$ [11]. Between these methods, the formation of complex structure by using macromolecules such as cyclodextrin is an often-used formulation strategy to increase the water solubility of hydrophobic drug substances [12,13]. However, this method should be suitable for the molecular structure or chemistry of drug substance as the inclusion complex can be obtained by means of interaction between host cyclodextrin molecule and the guest drug molecule according to their molecular conformation or size. Cyclodextrins are cyclic oligosaccharides consisting of six ( $a-C D)$, seven $(\beta-C D)$, eight $(\gamma-C D)$ or more ( $a-1,4)$ - linked D- glucopyranose units obtained by degradation of starch with the cyclodextrin glucosyl transferase, and they are known for over 100 years and have been used as pharmaceutical excipients for 20 years [14-16].

As it is shown in Figure 1, CDs are truncated cone or torus shaped molecules with peripheral hydrophilic zone and hydrophobic internal cavity [17]. By means of this molecular structure of CDs, they can act as complexing agents by taking up lipophilic moiety of the drugs into the hydrophobic internal cavity whilst the hydrophilic exterior facilitates high water solubility [18,19] and increase the water solubility of hydrophobic drug substances [20]. Moreover, CDs can take a role as a penetration enhancer for improving drug permeation and absorption through membrane barrier, and by this way they can improve bioavailability of drug substances [21,22].

On the basis of all these beneficial properties and functionalities of cyclodextrins, it was considered that the formation of inclusion complex with cyclodextrin provide the improvement of solubility and bioavailability of FB. For this purpose, the appropriate types of $\mathrm{CD}$ were investigated, and it was indicated that natural $\beta-C D$ and $H P \beta-C D$ were suitable and safe for using topical formulations of FB [23]. Also, FB has an affinity for these types of cyclodextrins that form inclusion complexes. To estimate the stability constant and to determine the molar ratio of FB: $\mathrm{CD}$ for preparing inclusion complex, phase solubility studies were performed.

The phase solubility studies is a traditional approach described by Higuchi and Connors in 1965 [24] to evaluate the effect of cyclodextrins on the solubility of hydrophobic drug substances according to phase solubility profiles (Figure 2). Moreover, this study provides to determine the stability constant $\left(\mathrm{K}_{\mathrm{c}}\right)$, complex type and stoichiometry of the equilibrium $[25,26]$. To obtain the equilibrium, a fixed amount of drug substance (guest molecule) is added to CD solutions of increasing concentration at the constant volume. The results of phase solubility studies, two types (A and B) of inclusion complexes can be obtained. A type profile indicates that a soluble inclusion complex is formed and B type profile indicates that an inclusion complex with limited water solubility is formed [27]. In type A, the equilibrium concentration of drug substances increases linearly with the $C D$ concentration. A type profile can be classified as $A_{P}, A_{N}$ and $A_{L}$ profile (Figure 2). While $A_{P}$ profile corresponds to a positive deviation from linearity, $A_{N}$ type profile corresponds to a negative deviation from linearity. In other words; $C D$ is more effective at high concentrations for the $A_{P}$ type profile while it is less effective for $A_{N}$ type profile. In the $A_{L}$ case, the equilibrium concentration of drug substances increases linearly with an increase in $C D$ concentration. The $A_{L}$ type profile indicates that the complex is of 1:1 stoichiometry, $\mathrm{K}_{\mathrm{c}}$ value of the complex can be calculated from the slope of the obtained isotherm and the saturation solubility $\left(\mathrm{S}_{0}\right)$ of the drugs in the complexation media. Moreover, the complexation efficiency (CE) which is the concentration ratio between free cyclodextrin and cyclodextrin in a complex can be calculated from the slope of isotherm [28].

According to the results of phase solubility studies, there are different ways to obtain inclusion complex such as freeze drying, supercritical fluid technology, kneading and co-evaporation techniques. Cirri et al. (2005) [29] prepared FB and methyl- $\beta$-cyclodextrin (Me- $\beta-C D$ ) complexes in the 1:1 molar ratio using kneading and co-evaporation techniques but they reported that the complexes prepared by co-evaporation and kneading methods required an organic solvent which may cause toxicity. For this reason, in this research freeze drying method was used to obtain inclusion complex. 


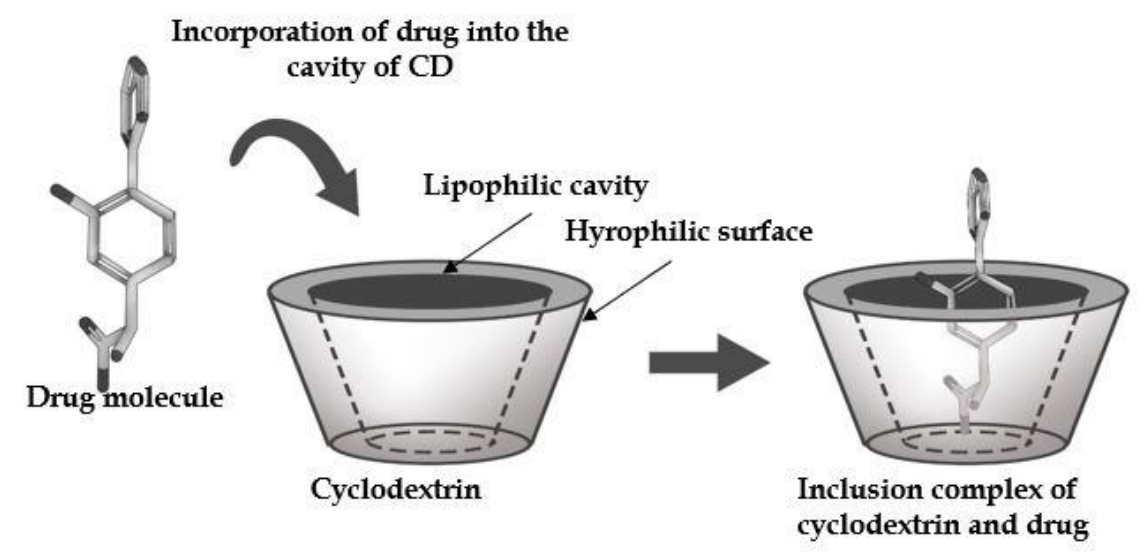

Figure 1. The formation of inclusion complex with cyclodextrin and drug molecule.

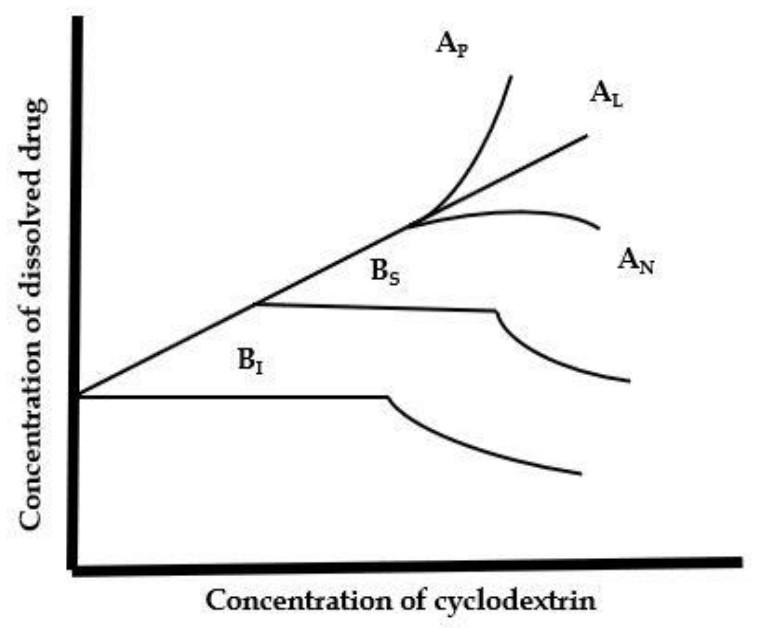

Figure 2. Phase solubility profiles and classification of complexes

The aim of the present study was to prepare the inclusion complex of FB with cyclodextrins and to increase the water solubility of FB by preparing an inclusion complex. According to phase solubility studies, the appropriate molar ratio of $\mathrm{FB} / \mathrm{CD}$ and the types of $\mathrm{CD}$ were determined. At the 1:1 molar ratio of FB: HP $\beta$ $\mathrm{CD}$, inclusion complex was prepared by using Freeze-drying method. Then the characterization studies such as Differential Scattering Calorimetry (DSC), X-ray Diffraction (XRD), Scanning electron microscopy (SEM) and Fourier Transform Infrared (FTIR) were performed to confirm the formation of the inclusion complex.

\section{RESULTS AND DISCUSSION}

\subsection{Determination of maximum wavelength and calibration curve of FB}

The absorbance of $5 \mu \mathrm{g} / \mathrm{ml}$ solution of FB was measured at 200-400 $\mathrm{nm}$ and the maximum wavelength of FB was determined to be $247 \mathrm{~nm}$. At this wavelength, the method was found linear in the range between 2 and $10 \mu \mathrm{g} \mathrm{mL}^{-1}$ presenting a good correlation coefficient $(\mathrm{r}=0.9999, \mathrm{n}=8)$. Accuracy and precision analysis showed good percentage recoveries $(95-105 \%)$ and low relative standard deviation (RSD $<2.00 \%$ ). Results of validation studies of UV spectrophotometric quantification method for FB in PBS ( $\mathrm{pH}$ 7.4) were to be linear, accurate, precise and robust.

The calibration curve of FB was obtained by measuring the absorbance in phosphate saline buffer ( $\mathrm{pH}$ 7.4). The graph of the absorbance versus the concentration $(\mu \mathrm{g} / \mathrm{mL})$ of FB showed the linearity (Figure 3$)$. The $R^{2}$ value of this equation is calculated and this value is found 0.9999 which indicates linearity. 


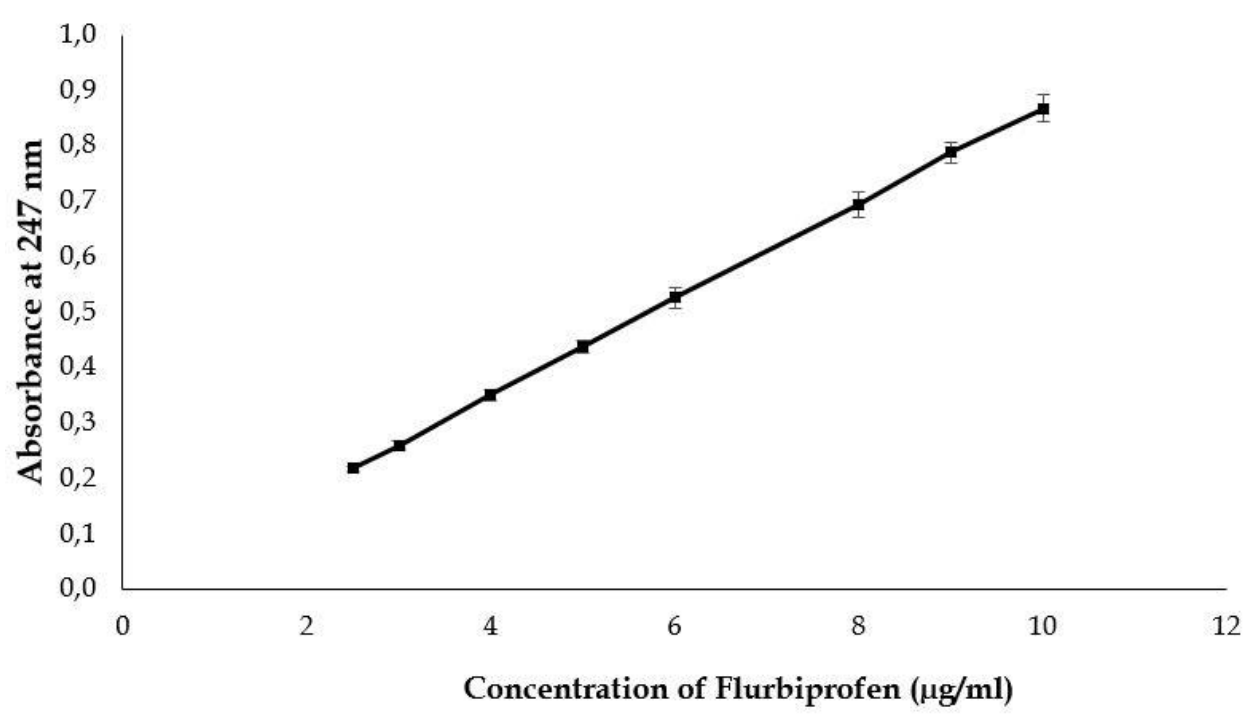

Figure 3. Calibration curve of flurbiprofen.

\subsection{Evaluation of phase solubility studies}

Flurbiprofen is a low water-soluble active substance and to overcome the solubility problem of $\mathrm{FB}, \beta-$ $C D$ and HP $\beta-C D$ were used in this research. The interaction of $\beta-C D$ and HP $\beta-C D$ with FB was evaluated using phase solubility studies in water and PBS at $37^{\circ} \mathrm{C}$. The phase solubilities were carried out by shaking the vials containing an excess amount of $\mathrm{FB}$ and solutions of $\beta-\mathrm{CD}$ and $\mathrm{HP} \beta-\mathrm{CD}$ in which the concentration ranged from 0 to $20 \mathrm{mM}$ according to the method described by Higuchi and Conner's. After that, the phase solubility diagrams were obtained by plotting the total amount of dissolved FB versus the increasing amount of cyclodextrin. (Figure 4 and 5). Figure 4 shows that the phase solubility plots obtained by using $\beta$-CD both in the water and PBS media at $37^{\circ} \mathrm{C}$. The $\mathrm{FB} / \beta-\mathrm{CD}$ solubility curve was a typical B-type phase solubility diagram which is indicative of the formation of inclusion complexes with limited water solubility. The similar diagram was observed for the inclusion complex of FB/ $\beta-C D$ in PBS media (Figure 4).

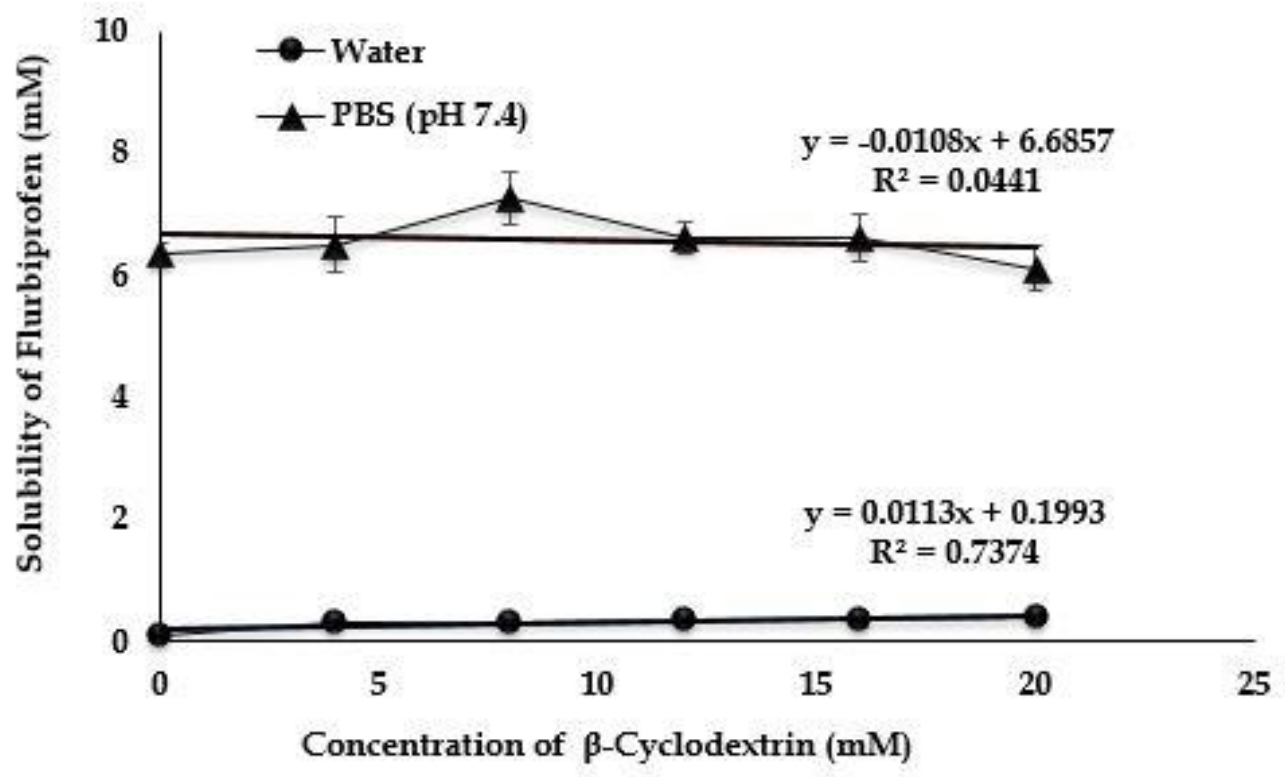

Figure 4. Solubility diagram of FB with $\beta$-Cyclodextrin.

In the first portion of the solubility diagram, by increasing $\beta-C D$ concentration in the $0-0.012 \mathrm{~mol}$, the apparent solubility of FB increased linearly from $0.0301 \pm 0.0003 \mathrm{mg} / \mathrm{mL}$ to $0.0894 \pm 0.0184 \mathrm{mg} / \mathrm{mL}$ in the water media. But after increasing the $\beta$-CD concentration from 0.012 to $0.020 \mathrm{~mol}$, plateau region was determined on the diagram which means the limited water solubility (approximately $0.09 \mathrm{mg} / \mathrm{mL}$ ) is observed instead of a 
linearly increasing FB solubility (Table 1). Moreover, it was determined that the results of increasing $\beta$-CD concentration from 0 to $0.008 \mathrm{~mol}$, and solubility of FB in the PBS media was increased linearly from $1.5526 \pm 0.0395 \mathrm{mg} / \mathrm{mL}$ to $1.7749 \pm 0.0392 \mathrm{mg} / \mathrm{mL}$. But after increasing the concentration of $\beta-C D$ from 0.008 to $00.020 \mathrm{~mol}$, a negative deviation on the plot and the limited solubility of FB was observed (approximately 1.6 $\mathrm{mg} / \mathrm{mL}$ ) (Table 1).

Table 1. Results of phase solubility studies of flurbiprofen with $\beta$-cyclodextrin (Mean $\pm S D, n=3$ ).

\begin{tabular}{ccc}
\hline $\begin{array}{c}\text { Concentration of } \boldsymbol{~}- \\
\text { cyclodextrin (mol) }\end{array}$ & $\begin{array}{c}\text { Solubility of Flurbiprofen }(\mathrm{mg} / \mathrm{mL}) \\
\text { Water }\end{array}$ & PBS $(\mathbf{p H ~ 7 . 4 )}$ \\
\hline 0 & $0.0301 \pm 0.0003$ & $1.5526 \pm 0.0395$ \\
0.004 & $0.0751 \pm 0.0308$ & $1.5885 \pm 0.0565$ \\
0.008 & $0.0764 \pm 0.0264$ & $1.7749 \pm 0.0392$ \\
0.012 & $0.0894 \pm 0.0184$ & $1.6144 \pm 0.0794$ \\
0.016 & $0.0912 \pm 0.0295$ & $1.6145 \pm 0.0658$ \\
0.020 & $0.0949 \pm 0.0163$ & $1.4953 \pm 0.0942$ \\
\hline
\end{tabular}

In Figure 5, the phase-solubility diagram was represented as the amount of total dissolved FB against the increasing concentration of $H P \beta-C D$. The $A_{L}$ type profiles which indicate a linear increase in the solubility of FB as a function of HP $\beta$-CD concentration in both water and PBS media were observed at the end of phase solubility studies. $\mathrm{R}^{2}$ values of plots were calculated as 0.9694 and 0.9898 for PBS and water media, respectively.

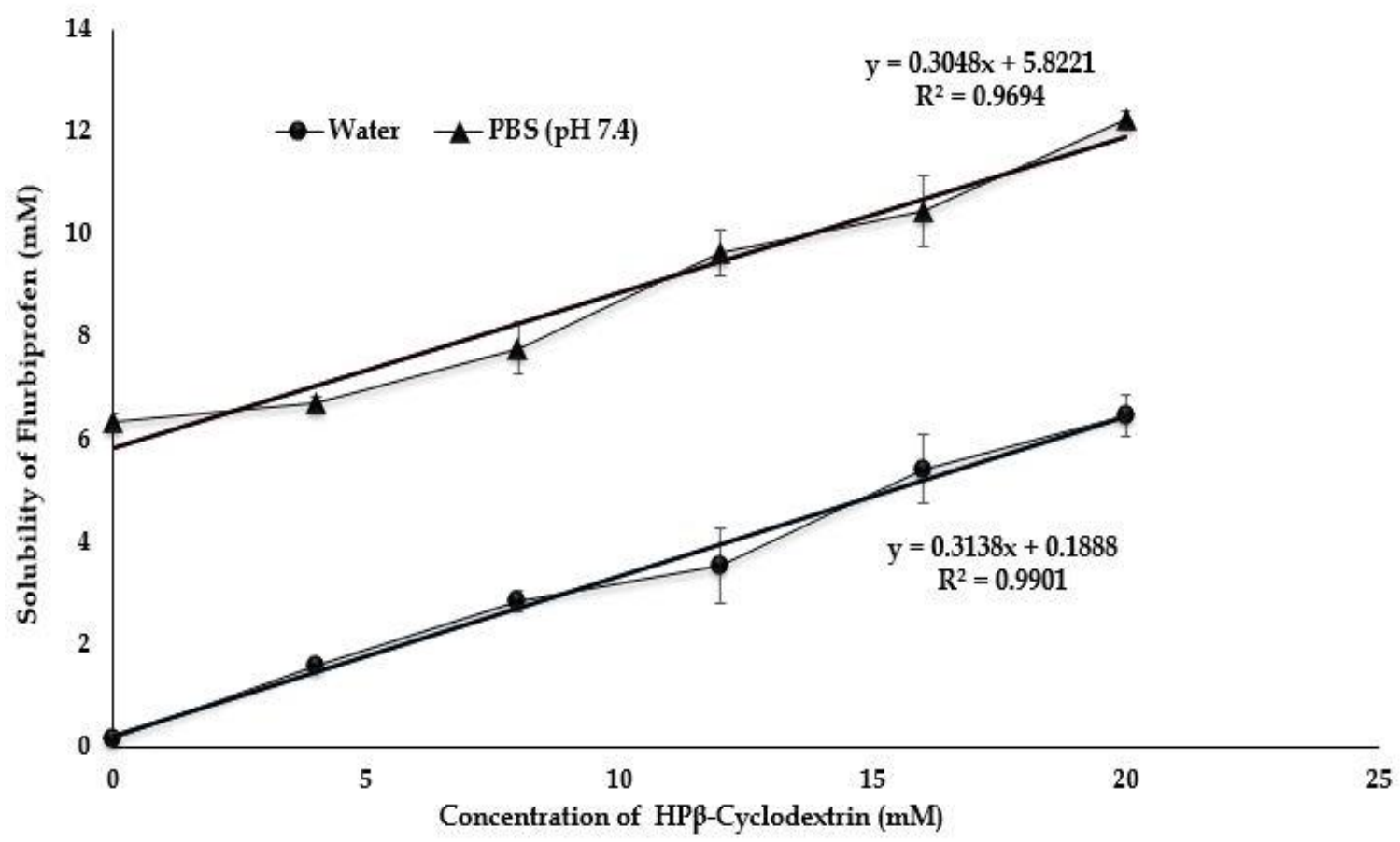

Figure 5. Solubility diagram of FB with HPß-Cyclodextrin.

Table 2 shows the effect of concentration of HP $\beta-C D$ on the solubility of FB $(\mathrm{mg} / \mathrm{mL})$ in PBS (pH 7.4) and distilled water. In the presence of HP $\beta-C D$, a continuous linear increase of FB solubility (from $0.0301 \pm 0.0003 \mathrm{mg} / \mathrm{mL}$ to $1.5818 \pm 0.1012 \mathrm{mg} / \mathrm{mL}$ ) was observed in water media, when the HPß-CD concentration was increased from 0 to $0.020 \mathrm{~mol}$. The similar results are indicated for the PBS media, the apparent solubility of FB increased linearly from $1.5483 \pm 0.0366 \mathrm{mg} / \mathrm{mL}$ to $2.9943 \pm 0.0392 \mathrm{mg} / \mathrm{mL}$, by increasing $\mathrm{HP} \beta-\mathrm{CD}$ concentration in the $0-0.020 \mathrm{~mol}$ range (Table 2). 
Table 2. Results of phase solubility studies of flurbiprofen with Hydroxypropyl- $\beta$-Cyclodextrin (Mean $\pm S D$, $n=3)$.

\begin{tabular}{ccc}
\hline $\begin{array}{c}\text { Concentration of } \\
\text { Hydroxypropyl- } \beta-\end{array}$ & \multicolumn{2}{c}{$\begin{array}{c}\text { Solubility of Flurbiprofen } \\
(\mathbf{m g} / \mathrm{mL})\end{array}$} \\
$\begin{array}{c}\text { Cyclodextrin (mol) } \\
\end{array}$ & Water & PBS (pH 7.4) \\
\hline 0 & $0.0301 \pm 0.0003$ & $1.5483 \pm 0.0366$ \\
0.004 & $0.3878 \pm 0.0197$ & $1.6390 \pm 0.0332$ \\
0.008 & $0.6932 \pm 0.0520$ & $1.8998 \pm 0.1237$ \\
0.012 & $0.8597 \pm 0.1765$ & $2.3554 \pm 0.1116$ \\
0.016 & $1.3226 \pm 0.1625$ & $2.5590 \pm 0.1691$ \\
0.020 & $1.5818 \pm 0.1012$ & $2.9943 \pm 0.0392$ \\
\hline
\end{tabular}

\subsection{Evaluation of stability constant $\left(\mathrm{K}_{\mathrm{c}}\right)$ and complexation efficiency $(\mathrm{CE})$ of complex}

The effects of the concentration of $\beta-C D$ and $H P \beta-C D$, in the range of 0 to $20 \mathrm{mM}$ on the apparent solubility of FB in water and PBS media were investigated by means of performing phase solubility studies (Figure 4 and 5). The most fundamental parameters in the quantitative analysis of interaction force between the $\mathrm{CD}$ and drug molecule and the stability of complex, are the apparent stability constant $\left(\mathrm{K}_{\mathrm{c}}\right)$ and the complexation efficiency (CE). The $\mathrm{K}_{\mathrm{c}}$ and $\mathrm{CE}$ of the FB/ $\beta-\mathrm{CD}$ and $\mathrm{FB} / \mathrm{HP} \beta-\mathrm{CD}$ complexes; were calculated from the linear part of solubility diagrams according to Eq. (1) and Eq. (2), respectively. The saturation solubility $\left(\mathrm{S}_{0}\right)$, the slopes of the phase solubility diagram $(\mathrm{m})$, the linear correlation coefficient $(\mathrm{R})$, the association constant $\left(\mathrm{K}_{1: 1}\right)$ and the complexation efficiency $(\mathrm{CE})$ in water and PBS media were given in the Table 3. While the stability constants $\left(\mathrm{K}_{c}\right)$ of FB/ $\beta$-CD inclusion complex in water and PBS were found 308.670 $\mathrm{M}^{-1}$ and $1.706 \mathrm{M}^{-1}$, stability constants $\left(\mathrm{K}_{\mathrm{c}}\right)$ of $\mathrm{FB} / \mathrm{HP} \beta-\mathrm{CD}$ inclusion complex in water and PBS were found $3764.697 \mathrm{M}^{-1}$ and $72.015 \mathrm{M}^{-1}$, respectively (Table 3). It means the interaction forces between FB and HP $\beta$-CD was stronger than the interaction forces between $\mathrm{FB}$ and $\beta-\mathrm{CD}$ for the formation of inclusion complex in water and PBS media.

The use of $H P \beta-C D$ provides to obtain $A_{L}$ type profile. In this type of profile, the stability constant was $\mathrm{K}_{1: 1}$ and it indicates that one molecule of FB forms an inclusion complex with one molecule of HP $\beta$-CD [32]. Thus it was considered that the formation of stable inclusion complexes between FB and HP $\beta-C D$ should be in a 1:1 molar ratio. Moreover, the $K_{1: 1}$ value of $F B / H P \beta-C D$ complex in water media was found higher than the $\mathrm{K}_{1: 1}$ value of $\mathrm{FB} / \mathrm{HP} \beta-\mathrm{CD}$ complex in PBS media. This result can be related to the low water solubility of FB compared to its solubility in PBS media. The water solubility of FB was increased from $0.0301 \pm 0.0003$ $\mathrm{mg} / \mathrm{mL}$ to $1.5818 \pm 0.1012 \mathrm{mg} / \mathrm{mL}$ by means of preparing inclusion complex with HP $\beta-C D$. As it is shown in Table 3, the $C E$ values which indicate the concentration ratio between $C D$ in complex and free $C D$ were also calculated from the slopes of phase solubility plots [33]. The CE values of FB/HP $\beta-C D$ complex were found higher than the $\mathrm{FB} / \beta-\mathrm{CD}$ complex in both media, especially in water media.

Table 3. Phase solubility datasets of FB in presence of $\beta-C D$ and HP $\beta-C D$ in water and PBS (pH 7.4).

\begin{tabular}{|c|c|c|c|c|c|c|c|c|c|c|}
\hline \multirow{2}{*}{ Media } & \multicolumn{5}{|c|}{$\begin{array}{c}\text { Solubility of FB in different media } \\
\text { with } \beta-C D\end{array}$} & \multicolumn{5}{|c|}{$\begin{array}{l}\text { Solubility of FB in different media } \\
\text { with } H P \beta-C D\end{array}$} \\
\hline & $\begin{array}{c}\mathrm{S}_{0} \\
(\mathrm{mM}) \mathrm{a}\end{array}$ & $\begin{array}{l}\text { Slope } \\
(\mathbf{m})^{\mathrm{b}}\end{array}$ & $\mathbf{R}^{2 c}$ & $\begin{array}{c}K_{1: 1} \\
\left(M^{-1}\right)^{d}\end{array}$ & $\mathrm{CE}$ & $\begin{array}{c}\mathrm{S}_{0} \\
(\mathrm{mM}) \mathrm{a}\end{array}$ & $\begin{array}{l}\text { Slope } \\
(\mathbf{m})^{b}\end{array}$ & $\mathbf{R}^{2 \mathrm{c}}$ & $\begin{array}{c}\mathbf{K}_{1: 1} \\
\left(\mathbf{M}^{-1}\right)^{d}\end{array}$ & $\mathrm{CE}^{\mathrm{e}}$ \\
\hline Water & 0.123 & 0.011 & 0.737 & 308.670 & 0.011 & 0.123 & 0.317 & 0.990 & 3.764 .697 & 0.463 \\
\hline PBS & 6.356 & 0.011 & 0.044 & 1.706 & 0.011 & 6.356 & 0.314 & 0.969 & 72.015 & 0.458 \\
\hline
\end{tabular}


These results of phase solubility studies absolutely demonstrated the advantage of using HP $\beta-C D$ instead of $\beta$-CD to obtain the inclusion complex with FB and improve the apparent water solubility of FB. Moreover it was determined that for the formation of inclusion complexes, the strong interactions between FB and $\mathrm{HP} \beta-\mathrm{CD}$ were occurred at 1:1 molar ratio in water. These results can be related to the molecular interaction between FB and CD hydroxyl groups. The hydroxyalkyl derivatives of $C D$ such as HP $\beta$-CD have higher water solubility compared to $\beta$-CD and they provide the conversion of the drug from a crystalline state into an amorphous state. In accordance with the results, the inclusion complex was prepared with HP $\beta$-CD and FB (1:1 molar ratio) in water media by using Freeze drying method and after that the presence of inclusion complex was confirmed by solid state characterization studies.

\subsection{Evaluation of solid state characterization studies}

\subsubsection{Scanning electron microscopy (SEM)}

SEM analysis were performed on coarse powder of $F B, H P \beta-C D$, their physical mixture and the inclusion complex to investigate the possible morphological changes caused by different treatments during the process. The scanning electron micrographs of coarse powder $\mathrm{FB}, \mathrm{HP} \beta-\mathrm{CD}$, their physical mixture and the inclusion complex were shown in Figure 6, respectively. FB particles existed in irregular shaped crystals at micro meter size with broad size distribution while HP $\beta$-CD was observed as homogenous amorphous spheres. In the physical mixture both the irregular shape of FB and the spherical shape of HP $\beta$-CD could be observed. The inclusion complex differed in morphology from FB and HP $\beta-C D$ and appeared in the form of irregular shaped particles. When the inclusion complex is prepared, the cavities in the HP $\beta-C D$ are filled by FB molecules. This result is an evidence of interaction between FB and HP $\beta$-CD in complex structure [31].

\subsubsection{Differential scattering calorimetry (DSC)}

The DSC curves of FB, HP $\beta-C D$, their physical mixture and the inclusion complex were shown in Figure 7. FB displayed one sharp endothermic peak at $114^{\circ} \mathrm{C}$, which means the melting point of the crystalline form. The broad endothermic peak of HP $\beta$-CD was observed at approximately $80{ }^{\circ} \mathrm{C}$ because of the loss of water and this result was similar to previously published studies [34-36]. The DSC thermogram of the physical mixture mainly showed the characteristic peaks of FB and HP $\beta$-CD. In contrast, the disappearance of sharp endothermic peak of FB could be found for the inclusion complex. This situation can be explained in the way that the inclusion complex was successfully prepared by means of freeze drying process and the FB particles are completely incorporated in the cavity of HP $\beta-C D$ ring molecule.

\subsubsection{Fourier transform infrared (FT-IR)}

The FT-IR is a useful technique providing evidence to confirm the presence of the inclusion complex. FT-IR spectrum of FB, HP $\beta-C D$, their physical mixture and the inclusion complex in the $4000-600 \mathrm{~cm}^{-1}$ regions were shown in Figure 8. As seen in the Figure 8, the characteristic sharp peaks of FB at 1694.7, 1414.7 and $1216.1 \mathrm{~cm}^{-1}$ were due to $\mathrm{C}=\mathrm{O}$ stretching, $\mathrm{O}-\mathrm{H}$ bending and $\mathrm{C}-\mathrm{F}$ stretching, respectively. The characteristic band of FB due to the hydrogen bonds of the carboxyl group appeared in the range of the $3400-2400 \mathrm{~cm}^{-1}$ [37]. On the other hand, the spectrum of $\mathrm{HP} \beta-C D$ is characterized by intense bands at $3300-3500 \mathrm{~cm}^{-1}$ due to O-H stretching vibration, while the vibration of the $-\mathrm{CH}$ and $-\mathrm{CH}_{2}$ - groups appears in the 2800-3000 $\mathrm{cm}^{-1}$ region [13]. For the physical mixture, both of the fingerprints of FB and CD were observed but it presented the reduction in intensity of the characteristic bands of FB for the low content of FB in the mixture. The FT-IR spectrum of the inclusion complex was found similar to be to the pure HP $\beta$-CD spectrum since FB was contained within the hydrophobic cavity of $\mathrm{HP} \beta-\mathrm{CD}$ molecule.

\subsection{4. $X$-ray diffraction $(X R D)$}

X-ray diffractometry is a useful method to confirm the formation of inclusion complex. The XRD patterns of inclusion complex should be clearly different from the patterns of each component. When the true complex has been formed, the reduction in thecrystalline state of powders was observed. This can be explained with the increase in the amorphous state during the formation process of the inclusion complex. The XRD patterns of $\mathrm{FB}, \mathrm{HP} \beta-\mathrm{CD}$, their physical mixture and the inclusion complex are shown in Figure 9. The XRD patterns of FB showed the crystallinity, while amorphous state was observed for HP $\beta$-CD. The patterns of physical mixture consisted of superimposed figures of pure FB and HP $\beta-C D$ with the peaks having lower intensity. These patterns showed most of the HP $\beta-C D$ character but some of the FB characteristics remained. It can be related to the dilution of FB in the mixture. On the basis of the inclusion complex patterns, just the amorphous characteristic of HP $\beta-C D$ was observed. The absence of specific crystallinity peak of FB provided the evidence of obtaining inclusion complex successfully. 

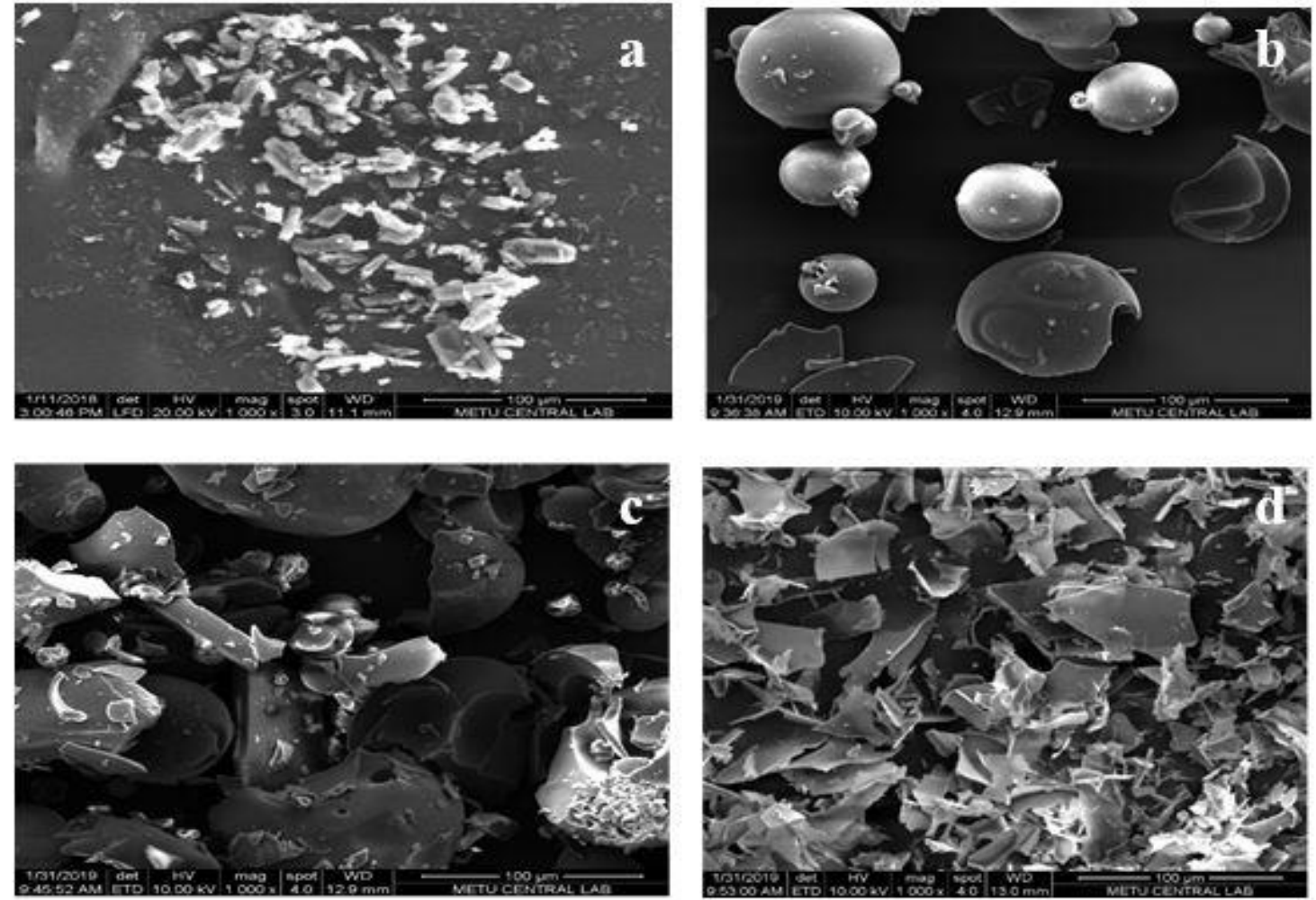

Figure 6. Scanning electron micrographs (magnitude 1000x) of (a) flurbiprofen, (b) HP $\beta-C D$, (c) their physical mixture, (d) inclusion complex.

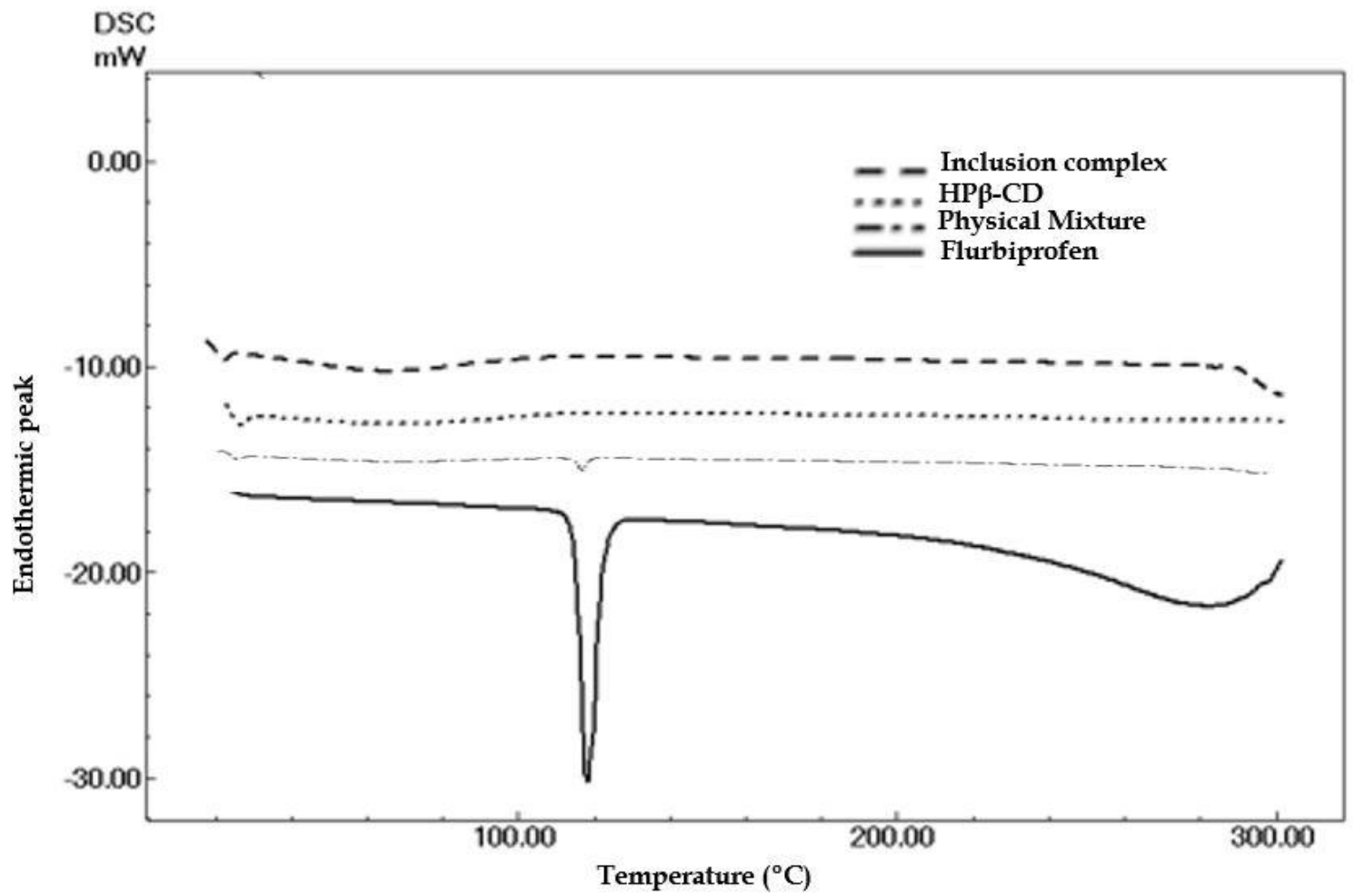

Figure 7. DSC thermograms of $\mathrm{FB}, \mathrm{HP} \beta-\mathrm{CD}$, their physical mixture, inclusion complex. 


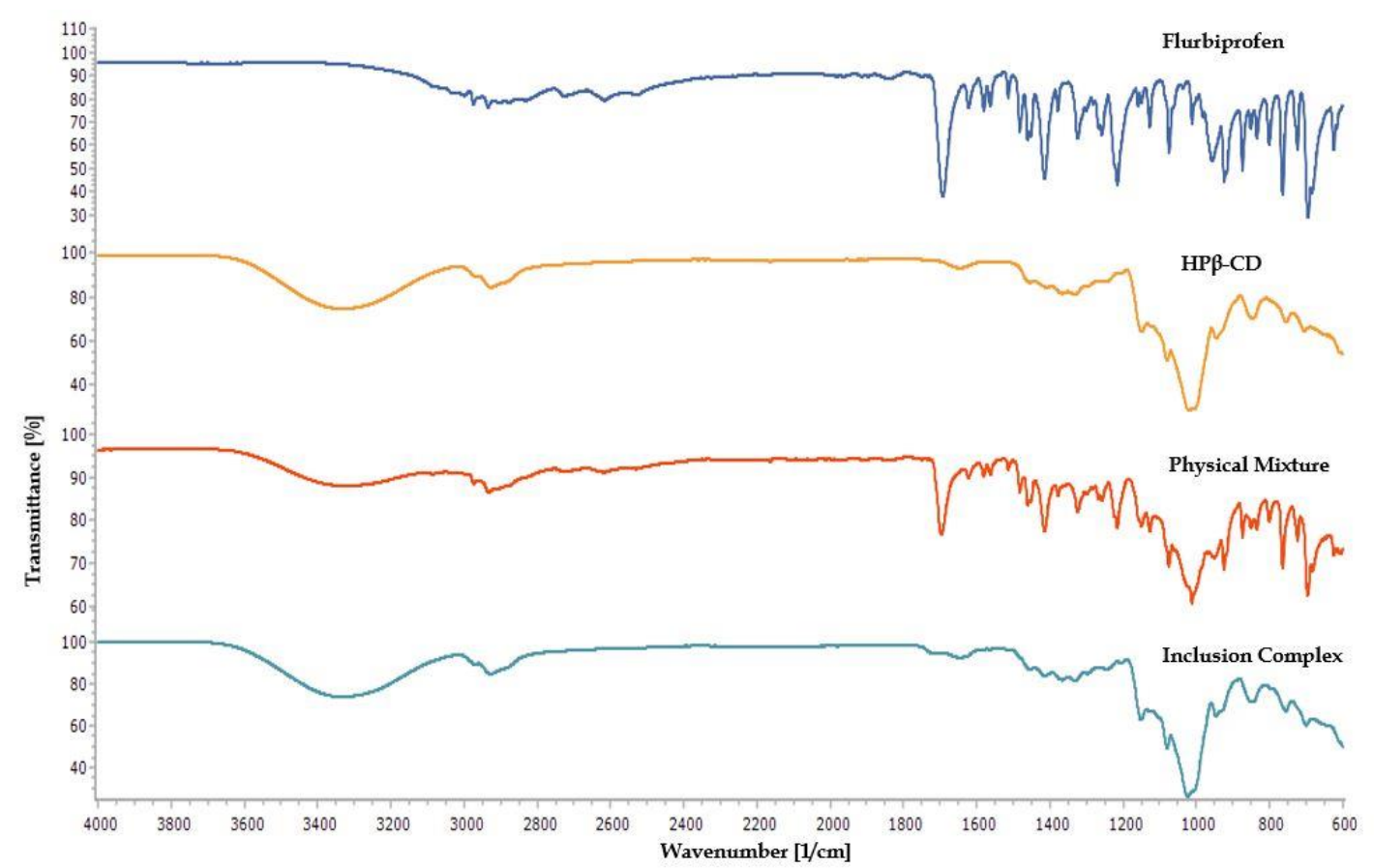

Figure 8. FT-IR spectrum of flurbiprofen, $\mathrm{HP} \beta-\mathrm{CD}$, their physical mixture, inclusion complex.

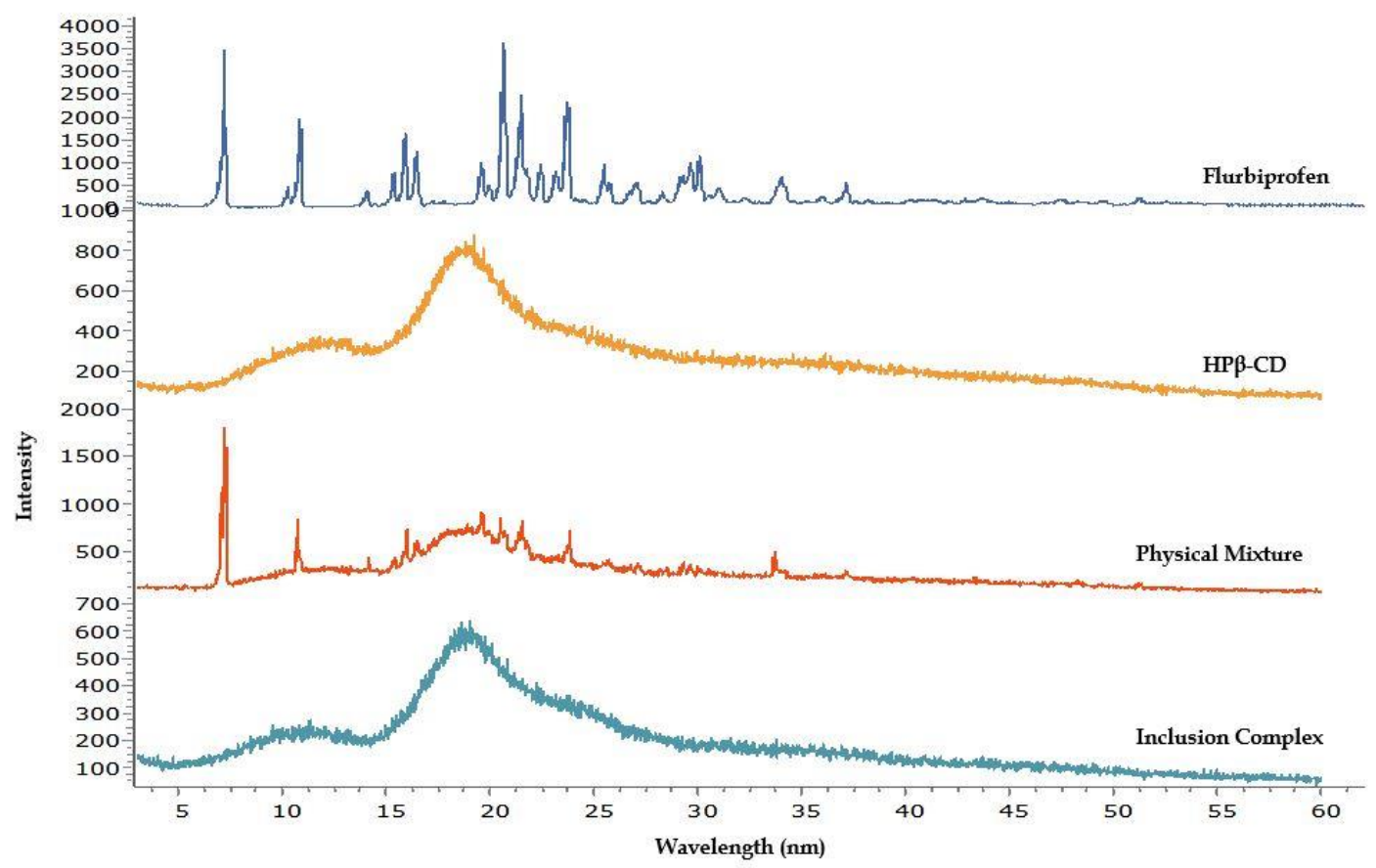

Figure 9. X-ray diffraction patterns of flurbiprofen, $\mathrm{HP} \beta-C D$, their physical mixture, inclusion complex.

As a result, the interaction between $\mathrm{FB}$ and $\mathrm{HP} \beta-\mathrm{CD}$ resulted in formation of inclusion complex and this inclusion complex increased the water solubility of FB. According to the phase solubility results the inclusion complex were prepared using 1:1 molar ratio of FB and HP $\beta-C D$ in water by using freeze drying method. After that, the presence of inclusion complex was investigated by DSC, XRD, FTIR and SEM analysis. The complex showed different physicochemical characteristics from the coarse powder of FB and HP $\beta-C D$ and the physical mixture of them. Thus the presence of inclusion complex was successfully confirmed and it was considered that the complexation with $\mathrm{HP} \beta-\mathrm{CD}$ is a promising approach to improve the solubility of low water soluble drug substances in pharmaceutical industry. 


\section{CONCLUSION}

In conclusion, hydrophobic molecules such as flurbiprofen have greater affinity into the cyclodextrin cavity. By means of specific structure of cyclodextrins; the physical and chemical properties of the hydrophobic molecule, such as solubility and stability can be improved. Thus, cyclodextrins have become important for pharmaceutical products. In this study, to solve the solubility problem of $\mathrm{FB}$, the inclusion complex of FB and HP $\beta-C D$ was successfully prepared. All the characterization studies also showed that the freeze-drying technique is suitable to produce the inclusion complex of FB and HP $\beta-C D$. Compared to the other techniques, the freeze-drying technique is possible to scale up and seems to be more applicable to the pharmaceutical industry. Moreover, this inclusion complex can be used to prepare novel nanotechnological formulations of several poorly soluble substances in order to increase solubility, stability and to improve bioavailability by allowing a dose reduction of the drug molecules applied.

\section{MATERIALS AND METHODS}

\subsection{Materials}

Flurbiprofen was kindly provided by Sanovel Pharma ${ }^{\circledR}$ (Istanbul, Turkey). Beta cyclodextrin and hydroxypropyl beta cyclodextrin were purchased from Sigma- Aldrich ${ }^{\circledR}(\mathrm{USA})$. Other chemicals were of analytical grade.

\subsection{Methods}

\subsubsection{Determination of maximum wavelength and calibration curve of $F B$}

UV spectrophotometer (Cary $60 \mathrm{Uv}$-Vis Agilent ${ }^{\circledR}$, Malaysia) was used to determine the amount of FB in the samples which are taken during the phase solubility studies. First of all, a stock solution $(100 \mu \mathrm{g} / \mathrm{mL})$ of FB in $\mathrm{pH} 7.4$ phosphate saline buffer was prepared. Accurately weighed $10 \mathrm{mg}$ of FB was transferred to a 100 $\mathrm{ml}$ volumetric flask, dissolved in $100 \mathrm{ml}$ phosphate saline buffer ( $\mathrm{pH}$ 7.4) by shaking manually for $10 \mathrm{~min}$. After that, appropriate volume $(0.5 \mathrm{ml})$ of standard stock solution of $\mathrm{FB}$ was transferred into a $10 \mathrm{ml}$ volumetric flask, diluted to get concentration of $5 \mu \mathrm{g} / \mathrm{ml}$. The resulting solution was scanned in the UV range (200-400 $\mathrm{nm}$ ). In spectrum FB showed maximum absorbance at $247 \mathrm{~nm}$. At this wavelength, the linearity, accuracy, precision, sensivity, repeatability, ruggedness was determined to obtain calibration curve of $\mathrm{FB}$ and to validate the UV method. The prepared stock solution of FB was diluted to get $2.5 ; 3 ; 4 ; 5 ; 6 ; 8 ; 9,10 \mu \mathrm{g} / \mathrm{mL}$. The absorbance values corresponding to these samples were measured in the spectrophotometer at $247 \mathrm{~nm}$ as maximum wavelength. When the concentration values are plotted against the absorbance values, the standard equation was obtained.

\subsubsection{Phase solubility studies}

The phase solubility studies were performed according to the method described by Higuchi and Connors [24]. Different concentrations of $\beta-C D$ and HP $\beta-C D$ were utilized to prepare solutions in PBS (pH 7.4) and in distilled water. An excess amount of FB was added to $10 \mathrm{~mL}$ of buffer solution and distilled water containing different amounts (0-4-8-12-16-20 mM) of $\beta-C D$ and HP $\beta-C D$. The volumetric flasks were placed and shaken at the $37^{\circ} \mathrm{C}$ in shaking water bath (Nüve ST 30, Turkey) until equilibrium is established (72 hours). The temperature was selected as $37{ }^{\circ} \mathrm{C}$ to increase the complexation coefficient [38] and to mimic the physiological temperature [39]. After 72 hours, the excess amount of $\mathrm{FB}$ was ultracentrifugated at $25^{\circ} \mathrm{C}$ for 45 min at $12000 \mathrm{xg}$ (relative centrifugal force) (Hitachi CS 150GXL, Japan) and the solutions were filtered using membrane filter (pore size $0.45 \mu \mathrm{m}$ ) and analysed by UV spectrophotometry at $247 \mathrm{~nm}$. The phase solubility curves were obtained by plotting the total concentration of dissolved FB against the respective concentration of $\mathrm{HP} \beta-\mathrm{CD}$ and $\beta-\mathrm{CD}$. By means of calculating the concentration of FB in $10 \mathrm{~mL}$ of distilled water and buffer solution at the absence of cyclodextrins $(0 \mathrm{mM})$, saturation solubility $\left(\mathrm{S}_{0}\right)$ of FB was determined.

\subsubsection{Calculation of stability constant $\left(K_{c}\right)$ and complexation efficiency $(C E)$}

The apparent stability constant $(\mathrm{Kc})$ was calculated from the slope of the phase solubility curves according to Equation (1), where the $S_{0}$ was the saturation solubility of $\mathrm{FB}$ in absence of $\mathrm{CD}$ at $37^{\circ} \mathrm{C}[24,30,31]$. According to Equation (2), complexation efficiency can be calculated from slope of the curves. 


$$
\begin{aligned}
& \text { Kc }=\text { Slope } /[\text { Sox }(1-\text { slope })] \text { (Eq. } 1) \\
& \text { CE }=\text { Slope } /(1-\text { slope }) \quad \text { (Eq. 2) }
\end{aligned}
$$

\subsubsection{Preparation of physical mixture}

Flurbiprofen and HP $\beta-C D$ according to 1:1 molar ratio were mixed in ceramic mortars. The obtained powder mixture was utilized as physical mixture of $\mathrm{FB}$ and $\mathrm{HP} \beta-\mathrm{CD}$.

\subsubsection{Preparation and lyophilization of the complex of flurbiprofen and HP $\beta-C D$}

Flurbiprofen and HP $\beta-C D$ according to 1:1 molar ratio were dissolved in $10 \mathrm{~mL}$ of distilled water and stirred at $37^{\circ} \mathrm{C}$ for $48 \mathrm{~h}$. After that, the mixture was filtered through $0.45 \mu \mathrm{m}$ membrane filter, the filtrate was put inside of the vials and then they were frozen at $-80{ }^{\circ} \mathrm{C}$ for 3 hours. The freeze-drying process (lyophilization) was applied at $-50{ }^{\circ} \mathrm{C}, 0.021$ mbar for 72 hours using Christ Alpha 1-2 LD ${ }^{\circledR}$ Freeze Dryer, Germany.

\subsubsection{Solid state characterization studies}

To confirm the presence of inclusion complex, the solid state studies such as differential scattering calorimetry (DSC), X-ray diffraction (XRD), scanning electron microscopy (SEM) and fourier transform infrared (FTIR) were performed after the lyophilization process.

\subsubsection{Scanning electron microscopy (SEM)}

The morphological properties of $\mathrm{FB}, \mathrm{HP} \beta-\mathrm{CD}$, their physical mixture and the inclusion complex were analyzed with scanning electron microscopy (SEM) (Quanta 400F Field Emission, USA). Prior to examination, powder samples were mounted onto a metal stub using double adhesive tape. Before scanning, the samples were coated with gold palladium in vacuum and observed at a voltage of 5-20 kV by SEM. All samples were magnified 1000x.

\subsubsection{Differential scanning calorimetry (DSC)}

DSC analysis was carried out for $\mathrm{FB}, \mathrm{HP} \beta-\mathrm{CD}$ and their physical mixture and the inclusion complex with Shimadzu DSC 60, Japan. Each powder weighed $(2 \mathrm{mg})$ and heated in the aluminum pans between $10^{\circ} \mathrm{C}$ to $300{ }^{\circ} \mathrm{C}$ temperature with heating rate of $10{ }^{\circ} \mathrm{C} / \mathrm{min}$. DSC thermograms were obtained under nitrogen flow of $100 \mathrm{~mL} / \mathrm{min}$ using Indium as temperature calibrator. In the same way, the empty pan was utilized as reference. Three different measurements were carried out for each sample, then extrapolated onset temperature and the average of maximum peak were determined.

\subsubsection{Fourier transform infrared (FT-IR)}

The FT-IR spectrum of FB, HP $\beta$-CD and their physical mixture and the inclusion complex were obtained with (Perkin-Elmer Spectrum 400 FT-IR, USA). All samples were scanned for absorbance over the range from $4000-600 \mathrm{~cm}^{-1}$ at the resolution of $4 \mathrm{~cm}^{-1}$.

\subsubsection{0. $X$-ray diffraction $(X R D)$}

The $\mathrm{X}$-ray powder diffraction patterns of $\mathrm{FB}, \mathrm{HP} \beta-\mathrm{CD}$, their physical mixture and the inclusion complex were collected with X-ray diffractometer (RigakuUltima-IV Powder Diffractometer, USA). The patterns were recorded by sample scan from $5^{\circ}$ to $120^{\circ} 2 \theta$ at a scan rate of $1 \%$ min and a voltage of $40 \mathrm{kV}$.

Acknowledgements: The author thanks to Prof. Dr. Nevin ÇELEBI for her contributions.

Author contributions: Concept - A.O.; Design - A.O.; Supervision - A.O.; Resources - A.O.; Materials - A.O.; Data Collection and/or Processing - A.O.; Analysis and/or Interpretation - A.O.; Literature Search - A.O.; Writing - A.O.; Critical Reviews - A.O.

Conflict of interest statement: The author reports no conflicts of interest. The author alone is responsible for the content and writing of this article. 


\section{REFERENCES}

[1] Rudrangi SRS, Kaialy W, Ghori MU, Trivedi V, Snowden MJ, Alexander BD. Solid-state flurbiprofen and methyl- $\beta$ cyclodextrin inclusion complexes prepared using a single-step, organic solvent-free supercritical fluid process. Eur J Pharm Biopharm. 2016; 104: 164-170. [CrossRef]

[2] Moya-Ortega MD, Alvarez-Lorenzo C, Concheiro A, Loftsson T. Cyclodextrin-based nanogels for pharmaceutical and biomedical applications. Int J Pharm. 2012; 428(1-2): 152-163. [CrossRef]

[3] Takagi T, Ramachandran C, Bermejo M, Yamashita S, Yu LX, Amidon GL. A provisional biopharmaceutical classification of the top 200 oral drug products in the United States, Great Britain, Spain, and Japan. Mol Pharm. 2006; 3(6): 631-643. [CrossRef]

[4] Charman W, Stella V. Transport of lipophilic molecules by the intestinal lymphatic system. Adv Drug Deliv Rev. 1991; 7(1): 1-14. [CrossRef]

[5] Heimbach T, Fleisher D, Kaddoumi A. Overcoming poor aqueous solubility of drugs for oral delivery. In: Stella VJ, Borchardt RT, Hageman MJ, Oliyai R, Maag H, Tilley JW (eds) Prodrugs. Biotechnology: Pharmaceutical Aspects, vol V. Springer, New York, 2007, pp.157-215. [CrossRef]

[6] Oh DH, Park YJ, Kang JH, Yong CS, Choi HG. Physicochemical characterization and in vivo evaluation of flurbiprofen-loaded solid dispersion without crystalline change. Drug Deliv. 2011; 18(1): 46-53. [CrossRef]

[7] Habib MJ, Phan MT, Owusu-Ababio G. Dissolution profiles of flurbiprofen in phospholipid solid dispersions. Drug Dev IndPharm. 1998; 24(11): 1077-1082. [CrossRef]

[8] Patel J, Patel A, Raval M, Sheth N. Formulation and development of a self-nanoemulsifying drug delivery system of irbesartan. J Adv Pharm Technol Res. 2011; 2(1): 9. [CrossRef]

[9] Zhang ZL, Le Y, Wang JX., Chen JF. Preparation of stable micron-sized crystalline irbesartan particles for the enhancement of dissolution rate. Drug Dev Ind Pharm. 2011; 37(11): 1357-1364. [CrossRef]

[10] Oktay AN, Karakucuk A, Ilbasmis-Tamer S, Celebi N. Dermal flurbiprofen nanosuspensions: Optimization with design of experiment approach and in vitro evaluation. Eur J Pharm Sci. 2018; 122: 254-263. [CrossRef]

[11] Willems L, Van der Geest R, De Beule K. Itraconazole oral solution and intravenous formulations: a review of pharmacokinetics and pharmacodynamics. J Clin Pharm Ther. 2001; 26(3): 159-169. [CrossRef]

[12] Schönbeck C, Madsen TL, Peters GH, Holm R, Loftsson T. Soluble 1: 1 complexes and insoluble 3:2 complexesUnderstanding the phase-solubility diagram of hydrocortisone and Y-cyclodextrin. Int J Pharm. 2017; 531(2): 504-511. [CrossRef]

[13] Nicolescu C, AramăC, Nedelcu A, Monciu CM. Phase solubility studies of the inclusion complexes of repaglinide with $\beta$-cyclodextrin and $\beta$-cyclodextrin derivatives. Farmacia 2010; 58(5): 620-628. [CrossRef]

[14] Mura P. Analytical techniques for characterization of cyclodextrin complexes in aqueous solution: a review. J Pharm Biomed Anal. 2014; 101: 238-250. [CrossRef]

[15] Jambhekar SS, Breen P. Cyclodextrins in pharmaceutical formulations II: solubilization, binding constant, and complexation efficiency. Drug Discov Today. 2016; 21(2): 363-368. [CrossRef]

[16] Tonkova A. Bacterial cyclodextrin glucanotransferase. Enzyme Microb Technol. 1998; 22(8): 678-686. [CrossRef]

[17] Muankaew C, Jansook P, Stefánsson E, Loftsson T. Effect of $\gamma$-cyclodextrin on solubilization and complexation of irbesartan: influence of $\mathrm{pH}$ and excipients. Int J Pharm. 2014; 474(1-2): 80-90. [CrossRef]

[18] Jansook P, Ogawa N, Loftsson T. Cyclodextrins: structure, physicochemical properties and pharmaceutical applications. Int J Pharm. 2018; 535(1-2): 272-284. [CrossRef]

[19] Rudrangi SRS, Bhomia R, Trivedi V, Vine GJ, Mitchell JC., Alexander BD, Wicks SR. Influence of the preparation method on the physicochemical properties of indomethacin and methyl- $\beta$-cyclodextrin complexes. Int J Pharm. 2015; 479(2): 381-390 284. [CrossRef]

[20] Erden N, Çelebi N. A study of the inclusion complex of naproxen with $\beta$-cyclodextrin. Int J Pharm. 1988; 48(1-3): 8389. [CrossRef]

[21] Carrier RL, Miller LA, Ahmed I. The utility of cyclodextrins for enhancing oral bioavailability. J Control Release. 2007; 123(2): 78-99. [CrossRef]

[22] Loftsson T, Duchene D. Cyclodextrins and their pharmaceutical applications. Int J Pharm. 2007; 329(1-2): 1-11. [CrossRef] 
[23] Loftsson T, Brewster ME. Cyclodextrins as functional excipients: methods to enhance complexation efficiency.J PharmSci. 2012; 101(9): 3019-3032. [CrossRef]

[24] Higuchi T, Connors K. Phase solubility diagram. Adv Anal Chem Instrum. 1965; 4: 117-212. [CrossRef]

[25] Loftsson T, Magnúsdóttir A, Másson M, Sigurjónsdóttir JF. Self-association and cyclodextrin solubilization of drugs. J Pharm Sci. 2002; 91(11): 2307-2316. [CrossRef]

[26] Brewster ME, Loftsson, T. Cyclodextrins as pharmaceutical solubilizers. Adv Drug Deliv Rev. 2007; 59(7): 645-666. [CrossRef]

[27] Hirayama F, Uekama K.Cyclodextrins and their industrial uses. Editions de Santé, Paris, 1987, 133

[28] Bilensoy E. Cyclodextrins in pharmaceutics, cosmetics, and biomedicine: current and future industrial applications. John Wiley \& Sons, 2011. [CrossRef]

[29] Cirri M, Rangoni C, Maestrelli F, Corti G, Mura P. Development of fast-dissolving tablets of flurbiprofen-cyclodextrin complexes. Drug Dev Ind Pharm. 2005; 31(7): 697-707. [CrossRef]

[30] Connors KA. Binding constants: the measurement of molecular complex stability. Wiley-Interscience, 1987. [CrossRef]

[31] Cetin E, Ilem D, Gundogdu E, Asikoglu M, Kirilmaz L. Correlation and in vitro studies on radioactive and nonradioactive albendazole- $\beta$-cyclodextrin complex tablets. Die Pharmazie-An International Journal of Pharmaceutical Sciences. 2011; 66(9): 672-676. [CrossRef]

[32] Govindarajan R, Nagarsenker MS. Formulation studies and in vivo evaluation of a flurbiprofen-hydroxypropyl $\beta$ cyclodextrin system. Pharmaceutical development and technology 2005; 10(1): 105-114. [CrossRef]

[33] BayrakcıMT, Ertul SE, Yilmaz M. Phase solubility studies of poorly soluble drug molecules by using Ophosphorylated calixarenes as drug-solubilizing agents. J Chem Eng Data. 2011; 57(1): 233-239. [CrossRef]

[34] Williams III RO, Mahaguna V, Sriwongjanya M. Characterization of an inclusion complex of cholesterol and hydroxypropyl- $\beta$-cyclodextrin. Eur J Pharm Biopharm. 1998; 46(3): 355-360. [CrossRef]

[35] Preiss A, Mehnert W, Frömming KH. Complexation of Hydrocortison with $\beta$-Cyclodextrin and Hydroxypropyl- $\beta$ Cyclodextrin. Archiv der Pharmazie. 1994; 327(11): 729-734. [CrossRef]

[36] Choudhury S, Nelson KF. Improvement of oral bioavailability of carbamazepine by inclusion in 2-hydroxypropyl- $\beta$ cyclodextrin. Int J Pharm. 1992; 85(1-3): 175-180. [CrossRef]

[37] Akyüz L, Duman F, Kaya M. Encapsulation of Flurbiprofen by Chitosan Using a Spray-Drying Method with In Vitro Drug Releasing and Molecular Docking. Turk J Pharm Sci. 2017; 14(1). [CrossRef]

[38] Hadziabdi'c J, Elezovi'c A, Rahi'c O, Mujezin I. Effect of cyclodextrin complexation on the aqueous solubility of diazepam and nitrazepam: phase-solubility analysis, thermodynami cproperties. Am J Analyt Chem. 2012; 3(12). [CrossRef]

[39] Russo E, Villa C. Poloxamer Hydrogels for Biomedical Applications. Pharmaceutics. 2019; 11(12): 671. [CrossRef] 